\title{
A FORMAÇÃO DE UMA CULTURA DEMOCRÁTICA NA GESTÃO DA ESCOLA PÚBLICA: ANALISANDO O DISCURSO DOS CONSELHEIROS ESCOLARES
}

\author{
LUCIANA ROSA MARQUES
}

\begin{abstract}
RESUMO: Este trabalho discute a formação de uma cultura democrática escolar a partir da análise do discurso dos membros do Conselho Escolar de três escolas públicas pernambucanas. Adota o conceito de cultura proposto por Hall (1997), que se articula ao conceito de discurso. Utiliza os referenciais das novas teorias do discurso, de corte laclauniano, para análise dos dados empíricos. Considera, ainda, que a gestão democrática não é instituída por leis ou normatizações, mas tem um caráter instituinte, podendo ser construída de diferentes formas em cada escola. Trata o discurso como prática social, que tanto pode manter como transformar as relações sociais. A análise dos dados empíricos revelou que as práticas discursivas constroem significados à gestão de cada escola e que são constitutivas de sua cultura. Verificou-se, ainda, que a gestão escolar vem se estruturando a partir de práticas democráticas que podem contribuir, também, no processo de democratização da sociedade.
\end{abstract}

Palavras-chave: Gestão escolar. Democracia. Cultura. Conselho escolar.

\section{The DeVelopment of A DEMOCRATIC CUlture IN PUblic SCHOOL ADMINISTRATION: ANALYZING THE SCHOOL COUNSELORS' DISCOURSE}

ABSTRACT: This article discusses a democratic culture development in public schools trough the analysis of School Council members' discourse in three public schools in Pernambuco. The culture concept proposed by Hall (1997) is adopted, which is joined to the discourse concept, using the reference to Discourse Theory for analysis of the empiric data. This article considers that the democratic administration is not instituted by laws, but has a institutionalize character, that could be built in different ways in each school. It treats the discourse as social practice, that can maintain or transform the social relationships. The empiric data shows that the discursive

* Apoio do CNPq.

** Doutora em Sociologia e professora do Departamento de Administração Escolar e Planejamento Educacional da Universidade Federal de Pernambuco (UFPE). E-mail: lmarques66@gmail.com 
practices build meanings to every school management, which are constituent of its culture. It was verified that the school administration are structured by democratic practices that they can contribute, also, in the democratization process of the society.

Key words: School administration. Democracy. Culture. School council.

\section{LA FORMATION D'UNE CULTURE DEMOCRATIQUE DANS LA GESTION DE}

L' ECOLE PUBLIQUE: ANALYSE DU DISCOURS DES CONSEILLERS SCOLAIRES

RÉSUMÉ: Ce travail discute la formation d'une culture démocratique scolaire à partir de l'analyse du discours des membres du Conseil Scolaire de trois écoles publiques de l'Etat du Pernambouc. Il adopte le concept de culture proposé par Hall (1997), qui s' articule avec le concept de discours. Il utilise les référentiels des nouvelles théories du discours, de coupure laclaunienne, pour l'analyse des données empiriques. Il considère, aussi, que la gestion démocratique n'est pas instituée par des lois ou des normatisations, mais elle a un caractère instituant, pouvant être construite sous différentes formes dans chaque école. Il traite le discours comme une pratique sociale, qui peut aussi bien maintenir que transformer les relations sociales. L'analyse des données empiriques a révélé que les pratiques discursives construisent des sens propres à la gestion de chaque école et qu'elles sont constitutives de sa culture. Il a été vérifié , d'autre part, que la gestion scolaire est en train de se structurer à partir de pratiques démocratiques qui peuvent contribuer, aussi, au processus de démocratisation de la société.

Mots-clés: Gestion scolaire. Démocratie. Culture. Conseiller scolaire.

\section{Introdução}

A

partir da década de setenta do século $X X$, o regime de acumulação fordista começa a viver uma crise fiscal e política, ao mesmo tempo em que são inauguradas transformações na base da economia capitalista em todo o mundo, particularmente o ocidental. Até então, tinha-se um modelo produtivo calcado na rígida hierarquia e especialização das tarefas, segundo o qual a produtividade podia ser aumentada por meio da decomposição e fragmentação dos processos de trabalho, a partir de conjunto rigoroso de práticas de controle, assim como de tecnologia e hábitos de consumo. A esse modelo produtivo corresponderia um determinado tipo de trabalhador, um tipo de homem.

São características, ainda, deste modelo produtivo a produção e consumo de massa e um modo de regulação que implica mecanismos que tratam de ajustar o comportamento contraditório e conflitante dos indivíduos.

A partir de 1973, quando se torna mais evidente a incapacidade desse modelo conter as contradições inerentes ao capitalismo, começam a emergir nos países centrais novas formas de organização da produção, fundadas na flexibilização: “A acumulação 
flexível se apoia na flexibilidade dos processos de trabalho, dos mercados de trabalho, dos produtos e padrões de consumo" (Harvey, 1996, p. 140). O modelo pós-fordista baseia-se no princípio da flexibilidade, como resultado da competição intensificada para reduzir os mercados; um processo centrado num trabalho contingente, negociado e essencializado, baseado na produção em equipe, na autogestão e em múltiplas, mas básicas, habilidades, além de modos de regulação governados pela ideologia do livre mercado, individualismo e caridade privada.

Assim, a especificidade de cada unidade produtiva passa a ser considerada: é a era da cultura organizacional. Passa-se de um modelo hierárquico claramente rígido e monocrático, para uma estrutura onde a concentração (elevada) de poder se dá em alguns poucos polos, quando o núcleo central da organização passa a exercer o controle pela definição dos canais de comunicação e informação e pela distribuição de recursos. Criam-se, assim, pequenas unidades descentralizadas, gozando de aparente autonomia. Para Gómez (2001), há a imposição de uma nova forma de organização cooperativa, caracterizada pela polivalência e flexibilidade das estruturas.

As transformaçoes ocorridas na base produtiva trazem consigo a "necessidade" de reformulação do aparato estatal. No modelo fordista, era necessário um Estado forte e controlador da economia, que fizesse investimentos em infraestrutura, necessários ao crescimento da produção e do consumo, através do qual se pretendeu regular o mercado, para manter o pleno emprego e uma economia orientada para a demanda. A administração estatal devia, ainda, sustentar a provisão pública das políticas sociais, oferecendo um "nível mínimo de vida", como elemento constitutivo da responsabilidade coletiva de todos os cidadãos e cidadãs.

No modelo neoliberal, por sua vez, o Estado deve ser mínimo, deixando-se à mão invisível do mercado a regulação econômica: "menos Estado e mais mercado" é a máxima neoliberal. Porém, a intervenção estatal torna-se necessária para compensar as falhas do mercado, tais como danos ao meio ambiente e combate ao monopólio, entre outras. Com relação às políticas sociais, inclusive as educativas, o Estado deve, paulatinamente, delegar ao setor privado e/ou público não estatal a responsabilidade por elas.

Esse movimento de limitação da atuação estatal acarreta o risco da perda do espaço público como direito. ${ }^{1}$ Dessa forma,

(...) podemos estar assistindo à transformação de direitos e obrigações com e dos cidadãos, em razão de seu status como cidadão, na aceitação de direitos e obrigações em razão de seu acesso ao mercado, ou seja, à compra e venda de serviços por quem pode, o cliente com recursos, comprá-los de quem o vende (...) a consequência mais preocupante da deterioração, e inclusive, da dissolução dos espaços e das instituições públicas, é o desamparo e a desmobilização que provocam, precisamente, nos menos favorecidos. (Gómez, 2001, p. 96) 
Essas mudanças encontram reflexos na forma proposta de gestão da educação. Com a adoção dos pressupostos neoliberais pelo poder central, a partir de 1995 começam a ser implantadas diretrizes no sentido de democratizar os sistemas escolares e a gestão das escolas. Assistimos, assim, a uma série de ações que visam tanto democratização da gestão das escolas públicas brasileiras, como dos próprios sistemas escolares, sejam eles estaduais ou municipais.

Cumpre considerar, contudo, que a discussão sobre a democratização da gestão escolar é uma demanda antiga de pesquisadores e trabalhadores da área, defendida por estes como um dos mecanismos importantes para se alcançar uma educação pública de qualidade, universal, como exercício de cidadania. Dessa forma, mesmo sendo implantada com base nos princípios neoliberais, a gestão democrática no sistema educacional público abre possibilidades para que se construa uma escola pública de qualidade, que atenda aos interesses da maioria da população brasileira, além de representar uma possibilidade de vivência e aprendizado da democracia, podendo, portanto, tomar um sentido diferenciado do proposto pelos fazedores de política. Nessa perspectiva, e admitindo o movimento dialético da história, podemos considerar que a implantação das novas diretrizes da política educacional não está, em princípio, pré-determinada e pode, por conseguinte, tomar sentidos diferenciados.

Tomando por base esta ideia, o presente trabalho teve por objetivo apreender os significados da democracia na gestão da escola pública. A coleta de dados foi realizada através de observações e entrevistas com membros do Conselho Escolar de três escolas da rede municipal do Cabo de Santo Agostinho - Região Metropolitana do Recife, Pernambuco. Parte-se do princípio de que as relações democráticas se consolidam a partir das práticas "cotidianas", ${ }^{2}$ construindo a cultura da escola. Desse modo, pode se constituir de forma diferenciada em cada escola. Buscou-se, assim, verificar como a gestão democrática se materializa nas escolas estudadas.

\section{A cultura escolar}

Consideramos, neste trabalho, que não existe um modelo de democracia de validez universal, sendo necessária a institucionalização de práticas democráticas nas diversas formas de relações sociais, que construiriam, assim, uma sociedade mais inclusiva. Tomando por base a ideia da indecibilidade e da incompletude da democracia, que é uma construção contínua e contingente que se dá através de práticas articulatórias nos diferentes espaços sociais, é pertinente o estudo da cultura escolar, tendo em vista que em cada escola a construção de relações democráticas pode se dar de forma diferenciada. 
Em seu estudo sobre a interpretação da cultura, Geertz (1989) demonstra a polissemia característica do conceito, assumindo-o a partir de uma perspectiva interpretativa, que busca significados, e não como um estudo experimental, à procura de leis. Tal posição provém de seu entendimento de que o homem é um animal amarrado a teias de significados que ele mesmo teceu; a cultura seria, portanto, a interpretação dessas teias.

O autor tece críticas, ainda, àqueles que defendem a existência de um caráter universal da cultura humana. Para ele, a produção cultural precisa ser situada nas relações sociais em que adquire significação, pois “o objetivo é tirar grandes conclusões a partir de fatos pequenos, mas densamente entrelaçados; apoiar amplas afirmativas sobre o papel da cultura na construção da vida coletiva, empenhando-as exatamente em especificações complexas" (Geertz, op. cit., p. 38).

Dessa forma, o estudo da cultura é sempre incompleto, na medida em que ela está em constante movimento, sendo criada e recriada, não podendo ser descritivo, mas interpretativo. Assim, considera a cultura como o tecido de significações em função das quais os homens interpretam suas experiências e guiam suas ações. A cultura poderia ser pensada como a articulação entre o que é instituído e o que é instituinte, caracterizando-se por um processo contínuo e ativo de construção da realidade, um fenômeno ativo, vivo, em que as pessoas criam e recriam seus mundos (Teixeira, 2002).

Para McLaren (1991), a cultura (da escola) é informada por determinantes específicos de classe social, ideologia e estruturas da sociedade, perspectiva que ampliaria a interpretação de Geertz. A cultura se expressa através de rituais interrelacionados e sistemas de rituais. $\mathrm{O}$ autor considera o ritual como um evento político e como parte das distribuições objetificadas do capital cultural dominante na escola, destacando, ainda, que "nas sociedades modernas as produções culturais superam as produções econômicas como base de valores, estilos de vida e visões de mundo compartilhadas" (McLaren, op. cit., p. 30).

No seu entendimento, os estudos sobre educação não têm conseguido explorar a maneira pela qual a cultura, como ação ritual, constitui comportamentos, principalmente porque os estudos antropológicos da educação, em sua maioria, têm considerado a escola como local politicamente neutro, sem problematizar sua relação com a sociedade. Assim, "qualquer análise dos rituais escolares deve ser colocada num contexto de cultura que problematize a relação entre escola, poder, conflito e

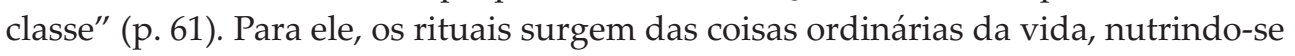
da experiência vivida, expressando-se como a "liturgia do cotidiano". Portanto, a explicação de um ritual é, inevitavelmente, o exame das dimensões simbólicas da vida social. 
Assim como Geertz, Gómez (2001) também parte das diferentes interpretações do conceito de cultura para construir a sua definição. Para ele, a cultura é

(...) o conjunto de significados, expectativas e comportamentos compartilhados por um determinado grupo social, o qual facilita e ordena, limita e potencia os intercâmbios sociais, as produções simbólicas e materiais e as realizações individuais e coletivas dentro de um marco espacial e temporal determinado. A cultura, portanto, é o resultado da construção social, contingente às condições materiais, sociais e espirituais que dominam um espaço e um tempo. Expressa-se em significados, valores, sentimentos, costumes, rituais, instituições e objetos, sentimentos (materiais e simbólicos) que circundam a vida individual e coletiva da comunidade. (p. 17)

Hall (1997) discute a centralidade do conceito de cultura na atualidade, articulando-o ao conceito de discurso. Epistemologicamente, a centralidade da cultura estaria nas mudanças paradigmáticas que a virada cultural provocou no interior das disciplinas tradicionais, no peso explicativo que o conceito carrega e no seu papel constitutivo e não dependente da análise social, o que a colocaria em um espectro mais abrangente de instituições e práticas. Para ele, "a cultura não é nada mais do que a soma de diferentes sistemas de classificação e diferentes formações discursivas as quais a língua recorre a fim de dar significação às coisas" (p. 29). O autor demonstra, ainda, que a cultura tem papel central na construção da subjetividade, da identidade e da pessoa como ator social. Dessa forma, práticas culturais e práticas discursivas seriam correlatas, ${ }^{3}$ pois "toda prática social tem condições culturais ou discursivas de existência. As práticas sociais, na medida em que dependem dos significados para funcionarem e produzirem efeitos, se situam dentro do discurso, são discursivas" (p. 33).

Ao inserir a discussão da cultura no espaço escolar, ou seja, em uma instituição social, Forquin (1993, p. 147) nos mostra que os conteúdos que "a escola transmite não são, com efeito, somente saberes no sentido estrito. São também conteúdos mítico-simbólicos, valores estéticos, atitudes morais e sociais, referenciais de civilização".

Consideramos, assim, que a escola não é um espaço de simples aquisição de conhecimentos, mas de aprendizados outros, como o das práticas democráticas. Os intercâmbios que se realizam no "cotidiano" escolar trazem efeitos no pensamento, sentimentos e condutas da comunidade escolar, ou seja, constroem identidades. ${ }^{4}$ Dessa forma, entendemos que as diretrizes das políticas de democratização se concretizarão na escola, locus de materialidade das políticas educacionais, e que serão implantadas a partir da rede de significações produzidas no "cotidiano" de cada escola, podendo (ou não) ser criada uma cultura democrática nas unidades escolares.

Entendemos, ainda, com base em Hall (1997), que

(...) cada instituição ou atividade social gera e requer seu próprio universo distinto de significados e práticas - sua própria cultura. Assim sendo, cada vez mais, o termo está sendo 
aplicado às práticas e instituições que manifestamente não são parte da "esfera cultural", no sentido tradicional da palavra. De acordo com este enfoque, todas as práticas sociais, na medida em que sejam relevantes para o significado ou requeiram significado para funcionarem, têm uma dimensão cultural.

A escola é uma organização da sociedade e sua cultura constitui-se em um prolongamento da cultura social. No entanto, isso não significa que as organizações escolares possam ser consideradas de modo uniforme, pois comportam diferentes sistemas de valores que criam realidades organizacionais diferenciadas. "A existência de padrões culturais nas organizações pode ser vista como fator de diferenciação das mesmas a partir da ação e da interação de seus membros" (Teixeira, 2002, p. 22). Assim, a cultura organizacional pode ser considerada a forma como as coisas acontecem no âmbito de uma instituição, dirigindo a atenção para o significado simbólico dos aspectos racionais da vida organizacional, o que permite o entendimento de significados subjetivos das estruturas e práticas, fundamentais ao entendimento do funcionamento "cotidiano" da organização. Nesse sentido, a organização pode ser considerada como uma realidade construída.

Assim, estudar a gestão das unidades escolares, a partir da análise do discurso, requer situá-la na dimensão do estudo da cultura escolar, ${ }^{5}$ pois é através da reapropriação, ressignificação e reinterpretação que as diretrizes da política educacional para a gestão das escolas serão relativizadas e adaptadas à realidade de cada unidade escolar, pois, como mostra Teixeira (op. cit., p. 40), com base no pensamento de Cândido, "se há uma organização administrativa igual para todas as escolas de determinado tipo, pode-se dizer que cada uma delas é diferente da outra, por apresentar características derivadas de sua sociabilidade própria".

Nesse sentido, os conselhos escolares, unidades gestoras da escola, de caráter deliberativo, são entendidos como um espaço político de construção social contingente, negociação de conflitos, confrontos e interesses, através de práticas discursivas, onde são construídos significados simbólicos, capazes de gerar mudanças no comportamento da comunidade escolar, ${ }^{6}$ em relação à gestão da escola e, portanto, na cultura escolar.

O conselho escolar é considerado uma estrutura discursiva, que constitui e organiza relações que se dão no interior da escola, através de práticas articulatórias que constroem sentido à gestão escolar. No entanto, os sentidos da gestão construídos através das práticas discursivas pelos conselheiros escolares têm a marca própria de cada escola, tendo em vista que ela representa uma organização, sendo, portanto, culturalmente diferente.

Nesse sentido, as práticas discursivas constroem significados à gestão de cada escola que são constitutivos de sua cultura, pois as mudanças nas organizações 
passam por uma mudança cultural e a gestão escolar democrática no Brasil seria uma prática inovadora, tendo em vista o caráter autoritário historicamente predominante na gestão das escolas públicas.

\title{
A teoria do discurso como forma de apreensão da realidade
}

O crescimento do interesse pela análise do discurso é, ao mesmo tempo, consequência e manifestação da "virada linguística", precipitada por críticas ao positivismo, pelo prodigioso impacto de ideias estruturalistas e pós-estruturalistas e pelos ataques pós-modernistas à epistemologia. Sua origem como crítica à ciência social tradicional significa que ela possui uma base epistemológica diferenciada das outras metodologias, o que é denominado construcionismo social, construtivismo ou construcionismo. Mesmo existindo diferentes abordagens de análise do discurso, todas partilham da rejeição da noção realista de que a linguagem é um meio neutro de refletir ou descrever o mundo, bem como da convicção na importância central do discurso, que é uma forma de ação no mundo, na realidade social que ele constrói.

Embora com muitas proximidades, tanto conceituais como metodológicas, Teoria do Discurso (TD) e Análise do Discurso (AD) não são exatamente uma mesma estratégia intelectual.

\begin{abstract}
A TD trabalha a dimensão da linguagem na análise de objetos empíricos pela sua inscrição numa problemática clara de implicação política e ontológica (...), enquanto a AD - embora não seja um ramo da linguística - pode ser inteiramente realizada no âmbito desta (...) sem maiores pretensões de fazer intervir hipóteses sobre como se constituem e transformam o social ou os atores sociais, ou de explicar o social a partir do discurso. A despeito de haver muitas definições de discurso na $\mathrm{AD}$, é importante admitir uma importante diferença entre estas e a TD (...) trata-se da rejeição que a TD faz da distinção entre discursivo e extradiscursivo e de sua definição formal de discurso que transcende o domínio da linguagem, tal como trabalhada na linguística e pressuposta como um dado empírico pelo mainstream das ciências sociais. (Burity, 2007, p. 74-75; destaque nosso)
\end{abstract}

Neste trabalho, o discurso é tomado como uma prática social, ou seja, como forma de construção social, cuja condição ontológica é a política, o que implica considerá-lo como uma forma de ação das pessoas sobre o mundo e sobre os outros, expressando as relações sociais que se colocam na sociedade. Constitui-se, portanto, em ações, seleções, escolhas, linguagens, enfim, todas as produções sociais das quais é expressão, podendo ser um caminho para o entendimento dos sentidos produzidos no "cotidiano". "O discurso, como um sistema de relações (entre significante e significado, entre linguagem e ação, entre elementos de diferentes outros discursos, etc.), encerra uma articulação orgânica entre língua e ato, entre o linguístico e o extralinguístico" (idem, ibid., p. 75). 
O foco de nosso trabalho são as práticas discursivas que correspondem a momentos ativos no uso da linguagem, momentos de ressignificação, de rupturas, de produção de sentidos e, portanto, de linguagem em ação, ou seja, como as pessoas produzem sentidos e se posicionam em relações sociais "cotidianas". Segundo Fairclough (2001, p. 66), em sua análise da obra de Foucault,

(...) o que é de maior significação aqui para a análise do discurso é a visão do discurso como constitutiva - contribuindo para a produção, transformação e a reprodução dos objetos da vida social. Isso implica que o discurso tem uma relação ativa com a realidade, que a linguagem significa a realidade no sentido de construção de significados para ela.

A análise de uma prática discursiva focaliza os processos de produção, consumo e mudança textual, o que exige referência aos ambientes econômicos, políticos e institucionais particulares nos quais o discurso é gerado. Portanto,

(...) não há como dissociar o processo de apreensão do real de processos de significação, os quais, por sua vez, implicam tanto em redes argumentativas quanto nas práticas concretas e nas instituições através das quais tais representações podem tornar-se significativas, compartilhadas ou impostas (conforme o façam por via democrática ou autocrática). Enfim, significa admitir uma acepção do termo que indica sua dinamicidade, o jogo das diferenças num sistema que altera os limites de sua própria configuração: discurso. (Burity, 1994, p.149; destaque do autor)

Dessa forma, todas as configurações sociais são significativas e os significados das palavras e práticas dependem do espaço discursivo, que é construído por práticas articulatórias, ${ }^{7}$ em que se colocam. Segundo Fairclough (op. cit., p. 91),

(...) o discurso contribui para a constituição de todas as dimensões da estrutura social que, direta ou indiretamente, o moldam e restringem: suas próprias normas e convenções como também relações, identidades e instituições que lhe são subjacentes. O discurso é uma prática, não apenas de representação do mundo, mas de significação do mundo, constituindo e construindo o mundo em significação.

O autor identifica três funções da linguagem e dimensões de sentido que coexistem em todos os discursos. A primeira é a função identitária, que se relaciona aos modos pelos quais as identidades sociais se estabelecem no discurso. A segunda função, a relacional, diz respeito à maneira como as relações sociais entre os participantes de processos discursivos são representadas e negociadas. Por fim, a função ideacional é referente aos modos pelos quais os textos significam o mundo e seus processos, entidades e relações.

Sendo uma prática social, o discurso é tomado como prática política, que transforma, mantém e estabelece as relações de poder e as entidades coletivas em 
que tais relações se colocam, havendo, portanto, uma competição para fixar sen$\operatorname{tidos}^{8}$ a configurações significativas particulares. Segundo Laclau e Mouffe (1989, p. 113),

(...) discursos são estruturas descentradas onde os sentidos são constantemente negociados e construídos. Esta estrutura descentrada, ou "totalidade" estruturada, ou, ainda, discurso, é o resultado de práticas articulatórias estabelecendo relações entre elementos com diferenças não articuladas discursivamente.

Esta perspectiva de discurso abre a possibilidade para reativação da origem política contingente do que é fixado e objetivamente apresentado, abrindo espaço para novos antagonismos e fixação de novos conteúdos e formas que não se colocavam até então, tornando possível, assim, a articulação de uma multiplicidade de discursos concorrentes e, consequentemente, da transformação dos agentes e práticas sociais. Assim, a prática de articulação, como deslocamento/fixação de um sistema de diferenças, penetra a densidade inteiramente material da multiplicidade de instituições, rituais e práticas através das quais uma estrutura discursiva é estruturada (Laclau \& Mouffe, 1985). Dessa forma, a prática discursiva tanto pode contribuir para a reprodução da sociedade, como para sua transformação.

\begin{abstract}
À medida que os produtores e os intérpretes combinam convenções discursivas, códigos e elementos de maneira nova em eventos discursivos inovadores estão, sem dúvida, produzindo cumulativamente mudanças estruturais nas ordens de discurso: estão desarticulando ordens de discurso existentes e rearticulando novas ordens de discurso, novas hegemonias discursivas. Tais mudanças estruturais podem afetar apenas a ordem de discurso "local" de uma instituição, ou podem transcender as instituições e afetar a ordem de discurso societária. O foco de atenção na investigação da mudança discursiva deveria manter a alternância entre o evento discursivo e tais mudanças estruturais, porque não é possível avaliar a importância do primeiro para os processos mais amplos de mudança social sem considerar as últimas, da mesma forma que não é possível avaliar a contribuição do discurso para a mudança social sem considerar o primeiro. (Fairclough, 2001, p. 128)
\end{abstract}

Nesta perspectiva, os conselhos escolares são tomados como estruturas discursivas, ou seja, práticas articulatórias que organizam e constituem as relações sociais. Não podem ser considerados, portanto, simplesmente como a expressão de algo já adquirido, mas como construtores de novos significados que podem ou não se fixar, de sentidos que se colocam como referências a partir da disputa por significados construídos nas relações sociais que se constroem na escola, contribuindo, assim, para a consolidação (ou não) de mudanças no discurso.

Os conselhos escolares organizariam as relações sociais referentes à gestão da escola, que vão construir práticas articulatórias que darão sentido à gestão escolar. Dessa forma, poderão ou não ser instituídas práticas democráticas na gestão da 
unidade escolar, dependendo dos sentidos fixados, e o conselho poderá ou não ser uma instância de transformação das relações sociais que se estabelecem no espaço escolar.

\section{A construção de uma cultura democrática na escola}

Visando perceber as práticas de gestão das unidades escolares da rede pública, foram pesquisadas três escolas da rede municipal do Cabo de Santo Agostinho, Região Metropolitana do Recife, onde, em pesquisa anteriormente realizada para dissertação de mestrado, encontraram-se indícios de democracia nas representações sociais dos membros do conselho escolar.

A escolha deste município deveu-se à composição de forças que estavam no poder à época da pesquisa de campo e que se colocavam no cenário progressista popular, o que sugere que as diretrizes da democratização não se fundamentariam na desresponsabilização do poder público com as políticas sociais, visando sua eficiência, eficácia e a garantia dos direitos individuais, mas sim no pressuposto do aprofundamento da vida democrática, da construção de uma escola cidadã, de uma escola pública de qualidade, que atendesse aos interesses da maior parte da população brasileira.

Duas das escolas estudadas, que denominamos "Margarida" e "Girassol", situam-se na área urbana do município. A escola Margarida atende 883 alunos do ensino fundamental de quinta a oitava série, distribuídos em quatro turnos. Dispõe de seis salas de aula, laboratório de informática, direção, secretaria, sala de professores, cozinha, depósito de merenda, quadra esportiva e oito sanitários. Sua estrutura física permite uma boa ventilação e apresenta bom estado de conservação. A escola Margarida conta com 23 professores em seu quadro, sendo que 91,3\% deles têm curso superior. A média de alunos por turma é de 42 alunos, que contam, em média, com 3,8 horas/aulas diariamente. Sua taxa de aprovação é de $86,2 \%$, a de reprovação é de $4,6 \%$, a de abandono, de $9,2 \%$, e a de distorção idade-série é de $52,8 \%$.

A escola Girassol funciona nos três turnos, atendendo 808 alunos, dos quais 82 estão na educação infantil, 139 na educação de jovens e adultos e 687 no ensino fundamental (primeira à oitava série). Dispõe de 12 salas de aula, sala de professores, secretaria e direção, além do pátio. Conta em seu quadro com 26 professores, dos quais $61,5 \%$ possuem curso superior, e apresenta uma média de 27,3 alunos por sala na educação infantil e 36, 7 no ensino fundamental, sendo, em média, 32 de primeira à quarta série e 41,5 de quinta à oitava série. A taxa de aprovação da escola Girassol no ensino fundamental é de $76,1 \%$, sendo $84,5 \%$ da primeira a quarta série e $68 \%$ da quinta à oitava série, e a de distorção idade-série é de $42,3 \%$ - 20,7\% da primeira à 
quarta série e 59\% da quinta à oitava série - havendo, ainda, uma taxa de abandono de $11,1 \%$ no ensino fundamental - 20,7\% da primeira à quarta série e 59\% da quinta à oitava série.

A terceira escola estudada, "Sempre Viva", localiza-se na área rural do município, atendendo 317 alunos, em três turnos, nas modalidades de educação infantil, ensino fundamental (primeira à oitava série) e educação de jovens e adultos, além de realizar atendimento às crianças vinculadas ao Programa de Erradicação do Trabalho Infantil (Peti) do governo federal em parceria com o município. Essas crianças participam, em um turno, das atividades regulares da escola em sala de aula e, no outro, realizam atividades de reforço, recreação e lazer, recebendo um auxílio financeiro. Dispõe, em sua estrutura física, de cinco salas de aula, sala de professores, direção, cozinha e sala de leitura (onde se encontra um razoável acervo de livros infantis) e salas externas, onde funcionam cursos profissionalizantes (costura e marcenaria), que atendem à comunidade, além de um galpão, no qual são desenvolvidas as atividades do Peti. É uma escola de estrutura física bastante reduzida e apresenta um ambiente bastante agradável. Chama atenção a sala de leitura, que é uma construção de madeira no hall interno da escola, em estilo de casa de brinquedo, muito colorida, na qual se encontra um acervo de livros infantis bem diversificados. Conta em seu quadro com 11 professores, dos quais dois estão na educação infantil (um com curso superior e outro não), quatro no ensino fundamental da primeira a quarta série (onde nenhum professor tem formação superior) e quatro no ensino fundamental da quinta a oitava série (onde todos possuem este nível de formação). A taxa de aprovação no ensino fundamental é de 87,9\% - 88,6\% da primeira a quarta série e $87,1 \%$ da quinta a oitava série - e a de distorção idade/ série é de $60,1 \%$ - 28,9\% da primeira a quarta e $84,7 \%$ da quinta a oitava série. $\mathrm{O}$ abandono na escola é bastante reduzido: $6,5 \%$, sendo $0,9 \%$ da primeira a quarta série e $84,7 \%$ da quinta a oitava série.

Neste estudo, partimos da perspectiva de que a prática discursiva envolve processos de produção, distribuição e consumo textual e de que os textos são produzidos de formas particulares, em contextos sociais específicos.

Assim, o discurso sobre democracia na escola foi considerado como uma prática social, na medida em que partimos do entendimento de que o ele tanto é constituído como constrói ativamente a sociedade. Nesse sentido, ele o discurso se coloca como uma prática articulatória que articula, desarticula e rearticula elementos discursivos, contribuindo para a reprodução ou transformação da ordem social existente, sendo, portanto, uma prática política, que envolve relações de poder.

A democracia na gestão da escola pública é uma prática inovadora, podendo estar inserida na categoria de mudança discursiva desenvolvida por Fairclough 
(2001, p. 128), para o qual "os processos sociocognitivos serão ou não inovadores e contribuirão ou não para a mudança discursiva, dependendo da natureza da prática social".

Assim, o objetivo deste trabalho é analisar os discursos e as práticas democráticas presentes na gestão da escola, que podem indicar mudanças na forma de sua gestão e, assim, contribuir (ou não) na mudança da própria sociedade. Para tal, foram analisadas as falas dos conselheiros e gestores municipais, a partir de entrevistas com a secretária municipal de Educação, com 14 conselheiros escolares e com três diretores; as ações comunicativas nas reuniões dos conselhos escolares e em um seminário de capacitação dos conselheiros, através de observações; e os documentos oficiais que tratam das políticas de descentralização/democratização da educação. Buscamos apreender, assim, os discursos e as práticas democráticas na gestão das escolas, que indicariam mudanças na gestão escolar e sua possível contribuição na democratização da própria sociedade.

Os conselhos escolares de todas as escolas estudadas são formados por representantes dos diferentes segmentos que compõem a comunidade escolar. No entanto, em alguns deles, estes representantes não foram eleitos, mas sim indicados, tendo havido, inclusive, em uma das escolas, uma pré-seleção dos alunos que seriam apontados para concorrer à eleição, em função de seu comportamento, utilizando-se, portanto, uma postura classificatória e excludente, fundamentalmente antidemocrática, para subsidiar a participação dos alunos no conselho. Este episódio nos mostra como a democracia pode ser impregnada de contradições.

É consenso, entre os conselheiros, que a importância do conselho escolar está na divisão de responsabilidades, tornando as relações da escola mais horizontais, deixando de haver uma concentração de poder na mão do dirigente. Parece, assim, estar sedimentada a concepção do conselho como instrumento e, mais ainda, como condição de democratização da gestão, que é de responsabilidade coletiva e não centrada na figura do diretor.

Percebemos ainda o destaque dado pelos conselheiros, quando indagados sobre a importância do conselho escolar, à maior integração entre pais e escola. Assim, através do conselho, a escola também cumpre uma de suas incumbências determinadas pela LDB,${ }^{9}$ no artigo 12, item VI, que é "articular-se com as famílias e a comunidade, criando processos de integração da sociedade com a escola". Pela via da democratização, a escola assumiria o seu caráter público, no sentido da oferta de uma educação de qualidade que atenda aos interesses da maioria da população brasileira.

Observamos muitas diferenças nos temas ${ }^{10}$ tratados nas reuniões dos conselhos escolares, o que reforçou nossa hipótese de que a democracia se constrói de forma diferenciada em cada escola, a partir da ação das pessoas, constituindo a sua 
cultura. Enquanto em uma das escolas se discute apenas questões financeiras nas reuniões do conselho, na outra se discute as financeiras e as administrativas e, na terceira, são discutidas as questões pedagógicas, financeiras e administrativas no conselho escolar. Percebemos que os assuntos tratados diferem de uma escola para outra, representando, portanto, avanços maiores ou menores na democratização da gestão escolar.

No mesmo sentido, a própria dinâmica das reuniões nos indica diferenças no processo participativo em cada uma das escolas. Em uma delas, as pessoas parecem estar "mais à vontade" nas reuniões do conselho escolar; em outra, percebemos uma centralização na figura da presidente do conselho (uma professora) e na do diretor da escola, ao passo que, na terceira escola, as reuniões não são sistemáticas.

Verificamos, ainda, que em todas as escolas a participação dos diferentes segmentos no conselho escolar se dá de forma igualitária e que as diferenças existentes são provenientes de características pessoais e não do segmento que a pessoa representa. Todos os conselheiros entrevistados consideraram que as opiniões de cada pessoa eram respeitadas da mesma forma, com o mesmo peso, sem haver a prevalência de opinião em função do segmento representado, assim como havia o respeito do dirigente pelas decisões do conselho, colocadas em prática pelo mesmo, indicando que a participação envolve a distribuição de poder e não apenas a colaboração.

Um estudo sobre democracia não poderia desconsiderar a questão da autonomia, na medida em que estes dois conceitos têm uma forte interrelação. Assim, "só a autonomia garante o poder, os recursos e a capacidade de decisão colectiva necessários ao funcionamento democrático de uma organização" (Barroso, 2004, p. 74).

A matriz discursiva em que se apoia a maior parte das entrevistas é a que aborda a autonomia em sua dimensão administrativa, com especial ênfase na determinação da aplicação de recursos financeiros recebidos pela escola, que, no entanto, muitas vezes, já vêm com sua utilização pré-determinada (custeio, capital, material permanente, material de consumo), o que restringe a liberdade da escola e a leva, por exemplo, a realizar campanhas de arrecadação de verbas para compra de equipamentos ou materiais dos quais realmente necessite. Ainda, para os conselheiros, a autonomia não pode ir de encontro ao cumprimento da legislação, envolvendo, portanto, liberdade, mas não independência. Dessa forma, pode-se fazer "tudo", dento do limite que é imposto pela legislação.

Por fim, buscamos identificar as mudanças geradas na gestão da escola após a implantação do conselho escolar. Os discursos dos conselheiros sugerem que houve muitas mudanças após a implantação dos conselhos escolares como órgãos gestores 
da escola, assim como houve também conflitos em seu processo de construção, embora se perceba que, na maioria dos discursos, os aspectos enfatizados são diferentes.

O primeiro sentido da mudança destacado refere-se à horizontalização das decisões na escola, que deixam de ser concentradas na pessoa do diretor e passam a ser de responsabilidade coletiva, inclusive havendo a participação na definição da utilização dos recursos financeiros e divulgação para todos sobre a aplicação dos mesmos. Assim, tanto os acertos quanto os erros passam a ser de responsabilidade coletiva, sendo compartilhados por toda a comunidade escolar. Este é o sentido que parece estar mais fixado nos discursos sobre as mudanças geradas pelo processo democrático da gestão da escola, pela via do conselho escolar. Percebemos, nestes discursos, o destaque da mudança das relações de poder na escola.

Além disso, no discurso dos conselheiros sobre as mudanças na gestão da escola, é destacado também o compromisso coletivo com a instituição, que é possibilitado pela participação. Assim, a participação passa também pelo comprometimento das pessoas com projetos coletivos, em que cada um tem suas responsabilidades que, se não forem cumpridas, comprometem o trabalho como um todo. Além disso, a prática participativa proporciona uma maior integração dos pais e da própria comunidade na escola.

No discurso dos conselheiros aparece, ainda, a melhoria do ensino como uma mudança proveniente da ação do conselho, possibilitada pela maior aproximação dos pais com a escola e com a própria direção e corpo docente. Esta aproximação fez com que as reivindicações dos pais fossem atendidas, uma vez que, anteriormente, estes não eram sequer recebidos pela direção ou pela Secretaria de Educação. Assim, a democratização possibilitou que a escola passasse a estar a serviço da comunidade a que atende, respondendo a seus interesses e demandas, concorrendo para que ela cumpra efetivamente o seu caráter público.

Da mesma forma, contribuindo com a melhoria da qualidade do ensino, aparece a recuperação/ampliação/reformas da estrutura física da escola, que, inclusive, possibilitou a ampliação da oferta de ensino em uma das instituições. No entanto, reforçando a ideia de que as políticas educacionais democráticas são essenciais para que a democracia possa ser construída nas unidades escolares, nesta escola, especificamente, após muita luta e conflito para a consecução da implantação de turmas de quinta a oitava série, houve o fechamento destas mesmas turmas, quando ocorreu a mudança de governo, o que provocou um arrefecimento do próprio conselho escolar, que se percebeu impotente. A dirigente, que havia sido eleita, encampou e defendeu as novas determinações da Secretaria de Educação, visando à sua permanência no cargo. Este episódio pode demonstrar quão difícil é o processo de construção democrática e, principalmente, a sua solidificação, que só poderá se dar com a confluência de vários fatores. 


\section{Considerações finais}

Nossa pesquisa demonstrou que, nas escolas estudadas, a democracia vem se solidificando como uma prática política, baseada em relações horizontais, contribuindo, portanto, para a formação política dos sujeitos sociais pertencentes ao espaço escolar. As entrevistas e observações realizadas nas escolas nos demonstraram que efetivamente a gestão vem se construindo de forma democrática, com a participação dos representantes dos diferentes segmentos da comunidade escolar, que são tratados de forma igualitária, com respeito a suas diferenças, que têm direito à voz, e que são, portanto, reconhecidos. Também percebemos que, independentemente do segmento que representam, os conselheiros têm suas argumentações respeitadas de igual forma.

Percebemos marcantes diferenças e várias semelhanças entre o que acontece nas escolas que estudamos e o que se verificou em outros espaços escolares (Lima, 2002; Werle, 2003; Santos, 2004; Souza, 2005). Tal achado reforçou nossa suposição de que a democracia se constrói como uma prática articulatória, ganhando diferentes sentidos nos diversos espaços sociais. Dessa forma, ela é uma construção das pessoas que formam a escola e não da escola como instituição em si.

Assim, nossa hipótese de que a construção de relações democráticas na escola se daria a partir da cultura de cada instituição se confirmou, demonstrando a existência de um campo político nas mesmas.

No entanto, não podemos entender a cultura escolar como algo perene, na medida em que ela é construída pelas pessoas que fazem a escola, ou seja, pela comunidade escolar e esta se modifica através do tempo, tanto em função do término do período escolar do corpo discente, quanto por questões burocráticas como transferências e aposentadorias dos profissionais da educação. Além disso, com as eleições diretas, os dirigentes passam a exercer mandatos de dois anos, podendo se reeleger uma única vez. Assim, a direção da escola, que, por seu papel de liderança, tem decisiva importância na construção da cultura da organização escolar, dispõe de um tempo determinado de exercício do mandato e, portanto, a mudança de dirigente pode se constituir em um fator indutor de mudança na cultura da escola.

A cultura tem papel central na construção da identidade dos atores sociais, que, por sua vez, constroem a cultura, que é contingente e contextual. Nosso estudo empírico confirmou os construtos de Hall que se baseiam na ideia de que cada instituição social gera seu próprio universo de significados e práticas, ou seja, sua própria cultura. Verificamos que, em cada uma das três escolas estudadas, a democracia está sendo construída de forma diferenciada, apesar de todas elas estarem submetidas à mesma política educacional, de fazerem parte da mesma formação discursiva. 
Cumpre ressaltar, ainda, que verificamos práticas democráticas em todas as escolas, embora estas se construam de forma diferenciada, alcançando também diferentes avanços. Assim, percebemos que as estruturas discursivas tanto são reproduzidas como transformadas na prática social.

É importante destacar também que a democracia, além de não ter um processo homogêneo de construção, pode apresentar distorções. Esta afirmação se verifica a partir de situações em que o conselho escolar foi "democraticamente utilizado" para justificar práticas antidemocráticas na escola, como a decisão pela expulsão de uma criança de 7 anos, cuja mãe havia agredido uma professora pelo fato de seu filho ter dito que a mesma havia batido nele. ${ }^{11}$ Assim, é possível se instrumentalizar espaços de participação no intuito da adoção de atitudes não democráticas, ou seja, excludentes e classificatórias. Este é um "perigo" que expressa o conflito inerente às relações democráticas, que não eliminam o poder, mas vivenciam-no pelo "pluralismo agonístico".

Consideramos que os conteúdos democráticos dos discursos verificados nas escolas estudadas contribuem com o processo organizativo dos atores escolares, estimulando, assim, a organização social. Na escola, além de conteúdos, aprendemos valores e práticas. Portanto, a institucionalização de práticas democráticas na gestão escolar forma sujeitos democráticos. Supomos que estes sujeitos não serão democráticos apenas na escola, mas em todos os espaços sociais aos quais pertençam, podendo, desse modo, contribuir na democratização dos mesmos e, consequentemente, da sociedade. Dessa forma, podemos inferir que as práticas discursivas em mutação, como as observadas neste trabalho, podem ser um elemento importante na mudança social.

\section{Notas}

1. Silva (2003, p. 40) demonstra como as bases ideológicas da política neoliberal foram sendo construídas desde o final da década de 1970, nas quais se observam mudanças na matriz discursiva dos diferentes grupos políticos no que tange à democracia. Dessa forma, para ela, "não se deve estranhar que a retirada do Estado da área social tenha sofrido tão pouca resistência por parte dos agentes envolvidos".

2. Cotidiano, neste trabalho, refere-se a dia a dia e não à teoria do cotidiano desenvolvida por Henri Lefebvre, Agnes Heller e Michel de Certeau, entre outros.

3. Segundo Hall (1997), o clássico exemplo desenvolvido por Marx acerca da diferença entre o trabalho animal e o trabalho humano (o pior dos arquitetos seria mais inteligente do que a melhor das aranhas), hoje poderia "ser chamado de concepção discursiva ou cultural da prática social".

4. Segundo Hall (1997, p. 40), “toda a nossa conduta e todas as nossas ações são moldadas, influenciadas, e, dessa forma, reguladas normativamente pelos significados culturais".

5. Segundo Hall (op. cit., p. 30), "dar à cultura um papel constitutivo e determinado na compreensão e na análise de todas as instituições e relações sociais é diferente da forma como a mesma foi teorizada por vários anos nas ciências sociais", em que foi considerada de forma objetiva, dada. Ao 
contrário, na atualidade, o significado das coisas é entendido não a partir da coisa em si, mas do sistema de classificação em que se insere. Argumenta ainda que, "de fato, não é que 'tudo é cultura', mas que toda prática social depende e tem relação com o significado: consequentemente, que a cultura é uma das condições constitutivas de existência dessa prática, que toda prática social tem uma dimensão cultural". Assim, a materialidade da realidade depende da produção de sentido.

6. Para Hall (op. cit., p. 39), a cultura "nos governa - regula nossas condutas, ações sociais e práticas e, assim, a maneira como agimos no âmbito das instituições e na sociedade mais ampla".

7. Para Laclau, uma estrutura discursiva não é uma entidade meramente "cognitiva" ou "contemplativa"; é uma prática articulatória que constitui e organiza as relações sociais. Uma prática articulatória consiste na "construção de pontos nodais - 'fixações parciais que limitam o fluxo entre significado e significante' (Mouffe, 1996, p.103) - que fixam parcialmente sentido; o caráter parcial dessa fixação procede da abertura do social, resultante, por sua vez, de um constante transbordamento de todo discurso pela infinitude do campo da discursividade" (Laclau \& Mouffe, 1985, p. 113).

8. Sentidos que são fixados de forma contingente, ou seja, são provisórios.

9. Lei de Diretrizes e Bases da Educação Nacional (Lei n. 9.394, de 20 de dezembro de 1996).

10. A importância de analisar os temas abordados nas reuniões dos conselhos escolares reside em que os assuntos tratados indicarão a distribuição de poder realizada no conselho. Assim, a análise dos temas discutidos, objeto de decisão coletiva, nos ajudou a entender como se dá a participação no conselho escolar.

11. Decisão que foi evitada pela Secretaria de Educação após uma conversa com os conselheiros e a referida professora.

\section{Referências}

BARROSO, J. A autonomia das escolas: uma ficção necessária. Revista Portuguesa de Educação, Braga, v. 17, n. 2, p. 49-83, 2004.

BRASIL. Lei n. 9.394, de 20 de dezembro de 1996. Estabelece as Diretrizes e Bases da Educação Nacional. Diário Oficial da União, Brasília, DF, 23 dez. 1996.

BURITY, J. Transbordamento do social: qual o jogo da democracia? In: SANTOS, R.; CUNHA, R.; COSTA, L.F. (Org.). Contemporaneidade e política. Rio de Janeiro: Sociedade do Livro; Instituto Astrogildo Pereira, 1994. p. 137-158.

BURITY, J. Teoria do discurso e análise do discurso: sobre política e método. In: WEBER, S.; LEITHÄUSER, T. (Org.). Métodos qualitativos nas ciências sociais e na prática social. Recife: Editora Universitária da UFPE, 2007. p. 72-83.

CUNHA, R.; COSTA, L.F. (Org.). Teoria do discurso e análise do discurso: sobre política e método. In: WEBER, S.; LEITHÄUSER, T. (Org.). Métodos qualitativos nas Ciências Sociais e na prática social. Recife: UFPE, 2007. p. 72-83.

FAIRCLOUGH, N. Discurso e mudança social. Brasília, DF: UnB, 2001.

FORQUIN, J.-C. Escola e cultura: as bases sócias e epistemológicas do conhecimento escolar. Porto Alegre: Artmed, 1993. 
GEERTZ, C. A interpretação das culturas. Rio de Janeiro: LTC, 1989.

GÓMEZ, A.I.P. A cultura escolar na sociedade neoliberal. Porto Alegre: Artmed, 2001.

HALL, S. A centralidade da cultura: notas sobre as revoluções culturais do nosso tempo. Educação \& realidade, Porto Alegre, v. 22, n. 2, p. 15-46, jul./dez. 1997.

HARVEY, D. Condição pós-moderna. 6. ed. São Paulo: Loyola, 1996.

LACLAU, E.; MOUFFE, C. Hegemony and socialist strategy. London: Verso, 1985.

LACLAU, E.; MOUFFE, C. Hegemony and socialist strategy: towards a radical democratic politics. London; New York: Verso, 1989.

LIMA, L. Organização escolar e democracia radical: Paulo Freire e a governação democrática da escola pública. São Paulo: Cortez, 2002.

MARQUES, L. A descentralização da gestão escolar e a formação de uma cultura democrática em escolas públicas. Recife: UFPE, 2007.

MARQUES, L. A teoria do discurso e o estudo da democracia na gestão da escola pública. In: WEBER, S.; FARIAS, M.S.B. (Org.). Pesquisa qualitativa nas ciências sociais e na educação: propostas de análise do discurso. João Pessoa: UFPB, 2008a. p. 109-128.

MARQUES, L. Contribuições da democracia radical e da teoria do discurso de Ernesto Laclau ao estudo da gestão da educação. In: MENDONÇA, D.; RODRIGUES, L.P. (Org.). Pós-estruturalismo e teoria do discurso: em torno de Ernesto Laclau. Porto Alegre: Edipucrs, 2008b. p. 89-113.

MCLAREN, P. Rituais na escola: em direção a uma economia política de símbolos e gestos na educação. Petrópolis: Vozes, 1991.

MOUFFE, C. O regresso do político. Lisboa: Gradiva, 1996.

SANTOS, T.F.A.M. Os colegiados escolares no contexto da democratização da gestão. Revista Brasileira de Política e Administração da Educação, Porto Alegre, v. 20, n. 2, p. 116-136, jul./dez., 2004.

SILVA, I.G. Democracia e participação na 'Reforma do Estado'. São Paulo: Cortez, 2003.

SOUZA, N.M.M. Gestão democrática da educação: entre as políticas oficiais e a prática escolar. 2005. Disponível em: <www.anped.org.br/27a.htm>. Acesso em: 9 nov. 2005.

TEIXEIRA, L.H.G. Cultura organizacional e projetos de mudança em escolas públicas. Campinas: Autores Associados; São Paulo: Umesp; Anpae, 2002. 
A formação de uma cultura democrática na gestão da escola pública...

WERLE, F.O.C. Conselhos escolares: implicações na gestão da escola básica. Rio de Janeiro: DP\&A, 2003.

Recebido em 3 de janeiro de 2011.

Aprovado em 27 de junho de 2012. 